\title{
Enduring relations: exploring a paradox of new materialism
}

Chris Fowler and Oliver J. T. Harris

\section{Abstract}

In this paper we examine tensions between understandings of material things as either bundles of relations or as things-in-themselves. Rather than take either of these positions, we instead set out an argument for approaches that allow us to modulate between these understandings whilst treating both as relational. Taking such a position allows us to understand how things endure through time without returning to any notion of essence. We explore the theoretical arguments through an analysis of one particular enduring material phenomenon: the Neolithic chambered tomb of West Kennet.

\section{Key words}

Relations, time, materials, waves, particles, indeterminacy, being, becoming

\section{Introduction}

How can we best describe a Neolithic chambered tomb like West Kennet, Wiltshire? Is it a monument, a burial site, a singular place in the landscape? Or is it a bundle of relations tying together stone, earth, bodies, bones, architectural forms and even archaeologists, photographs, academic articles and many more elements, each themselves a meshwork of relationships? Across a range of disciplines engaging with material culture a 'new materialism' is emerging, allied with perspectives described as post-humanist and nonrepresentationalist. From thinking through the engagements between humans and animals (Haraway, 2008) via complex interactions that lead to blackouts across the US (Bennett, 2010), the relational emergence of authenticity in heritage objects (Jones, 2010) and the intricate world of historical buildings as assemblages (e.g. Edensor, 2011; Jones and Yarrow, 2013), to the seemingly simple processes of water drying on a stone (Ingold, 2011), a more intermingled world of relational materials and relational properties is emerging. At the same time though we are called to attend to objects for what they are, to their 'individual qualities' (Olsen, 2010: 156) and to embrace a fundamentally object oriented ontology that centres on the notion of a withdrawn essence (Harman, 2011a). In this world of objects above all else, to attempt to understand an example such as a humble billiard ball by exploring scales smaller than these objects mistakenly 'undermines' them, while thinking at any larger scale erroneously 'overmines' them (Harman, 2011a). Thus we are faced with the questions we 
started with. Do objects exist and then enter into relations? Or are the relations themselves primary? These are seemingly central yet irreconcilable approaches that cut to the heart of material culture studies.

Debates within archaeology can be taken as a case study of the growing importance of new approaches to materials and materiality. Studies of everything from Palaeolithic technology, via Bronze Age pottery, to the practice archaeology itself and beyond have explored the relational emergence of things, materials and their properties (e.g. Conneller, 2011; Hodder, 2012; Lucas, 2012; Marshall and Alberti, 2014; Olsen, 2010; Olsen, 2012; Olsen et al., 2012; Watts, 2013; Webmoor and Witmore, 2008; Witmore, 2007; for reviews of these different approaches see Fowler, 2013: ch. 2; Harris, 2013, 2014). These writers and others draw on an interrelated set of theoretical positions, particularly those produced by Whitehead (1964), Deleuze and Guattari (2004), DeLanda (2006), Harman (2011a), Latour (1999), Ingold (2011) and Barad (2007). One tendency in these approaches is increasingly to see material things as an ever-changing bundle of relations, to emphasise the way they are constantly fluid and in flux. This has helped overcome an older view of material things simply as inert objects, brought to life only through human agency. Yet this response risks preventing us from understanding how material culture comes to endure (Olsen, 2010: 158-9), how things can emerge as bounded entities. It is this realisation that has caused some people to turn to essences, to postulate a 'withdrawn' quality of things (e.g. Olsen 2010; Witmore 2012). This inevitably places objects in advance of the relations they enter into, as Olsen (2010:157) explicitly recognises, presenting an obstacle to understanding the historical emergence of particular things. Even singular accounts have yet to really resolve this tension internally, switching between embracing a Whiteheadian view in which new things constantly emerge (e.g Olsen et al., 2012, 119-120) and a desire to detect a withdrawn quality to objects that allows them to endure (e.g. Olsen et al., 2012: 121). Indeed, as archaeologists attempting to understand how the distant past manifests itself in the present we are constantly faced with this seemingly irresolvable difficulty. One reading of Latour, drawing on Alfred North Whitehead, might seem to suggest that relations do not endure, but rather are constantly shifting: new relations make new networks, new things (Harman, 2009; Olsen, et al. 2012: 119-120; Witmore 2012). Does this mean then that archaeologists can only trace those relations that are constituted in the present, as Holbraad (2009) has implied? Or do some relations endure through time? If the latter, how can we understand this endurance? Can we 
do this without resorting to an idea of an object-like essence that sustains material things through the ages?

In this paper we will explore the paradox of deciding whether to approach things as ongoing relational processes or as bounded entities. Rather than attempting to pick one of these over the other we will argue that it is essential we recognise the importance of both to archaeology and material culture studies. Above all we will explore the processes by which we can shift modes between these different forms, but without resorting to a non-relational essence. We will exemplify this by drawing on the work of Karen Barad and using her analysis of how electrons are determined as either a particle or as a wave as a strategic model for thinking about material culture. We do not do this to champion any single approach, but rather seek to explore how some of the common problems faced by many current approaches to things and relations can be rethought. We will argue that moving between multiple modes of engagement is needed in order to make sense of material culture. In the second half of the article we will exemplify the approach by considering the archaeological site of West Kennet chambered tomb.

\section{Debates over relationality}

The contradictions and tensions we describe above are revealed in the contrasting interpretations of the work of Bruno Latour, perhaps the most famous exponent of new approaches to material things, which have surfaced in both archaeology and anthropology. These interpretations draw differently on what the philosopher Graham Harman (in Latour, et al. 2011) has identified as the central paradox in Latour's work. On the one hand Latour is a realist philosopher, and his work is full of real people, objects, things and institutions mediating each other's engagement with the world. On the other he is truly a philosopher of relations. None of these objects in his studies pre-exist their relations, each is constituted from a networks of actants ${ }^{\mathrm{i}}$.

This paradoxical position (in which objects both emerge from and enter into relations) has led to two apparently opposed readings of Latour. The first, by anthropologist Tim Ingold, argues that Latour treats objects as concrete entities pre-existing relations they enter into (see also Alberti and Marshall, 2009: 348). In contrast, philosopher Graham Harman (Harman, 2009; Harman in Latour et al., 2011), whilst identifying the paradox referred to above, concentrates his fire on what he sees as Latour's total dependence on relations ${ }^{\text {ii }}$. For Harman, Latour 
reduces everything to relations, the opposite of the critique thrown at him by Ingold. How is it possible for thinkers as insightful as Harman and Ingold to read Latour so differently? It is our contention that the critiques offered do not reveal fundamental flaws in Latour's work, but rather open up a productive space to pursue the emergence of entities from relations and relations from entities. To make this point we now set out in more detail the two competing visions of Latour's attitude towards entities and relations.

\section{Ingold's Latour provokes a rebuttal from the Spider}

On the surface there seems to be much in common between the meshworks that Ingold endorses and the networks of Latour. Ingold (2011) views his meshworks emerging from the intersections of a series of lines. These lines, Ingold argues, are like rivers, tracing the progress and intersection of different kinds of becoming. In this Ingold (2011:83) draws on Deleuze and Guattari (2004) and their concepts of lines of becoming and lines of flight. Where such lines coalesce, becoming interwoven, they form bundles which Deleuze and Guattari (2004: 287-9) term 'haecceities': haecceities have a specific 'individuated' character. While they state that haecceities are 'a mode of individuation very different from that of a person, subject, thing or substance' (ibid.: 288) they also conclude that all of these are also haecceities since they are events (ibid.:289). Haecceities are assemblages occurring, and exhibiting distinctiveness as they occur. However, Ingold draws a series of clear contrasts between his work, and his reading of Latour. As he puts it, "[t]he critical distinction between the lines of flow of the meshwork and the lines of connection of the network has been persistently obscured' (Ingold, 2011: 85). Latour, Ingold argues, treats entities as existing prior to relations which connect up networks. In other words there are objects, which then come into contact with one another forming relations. Ingold makes this most explicit in his account of an amusing encounter between a philosophically inclined ant (standing for Latour) and a similarly intellectual spider taking Ingold's place in the dialogue. For the ant, spider declares, "every "relation" in the network, then, is a connection between one thing and another' (Ingold, 2011: 91, original emphasis). The spider contrasts this with her web, which is made up of lines 'along which I live' (Ingold, 2011: 91, original emphasis). The opposition of 'between' and 'along' is one Ingold returns to repeatedly as the key difference as he sees it between meshworks and networks (but see Latour, 1999: 71 and endnote v below). For the purposes of this paper, we will term this version of Latour, where objects pre-exist relations, 'Ingold's Latour'. A house, for Ingold's Latour, therefore pre-exists the arrival of the people 
who live in it. The two then form a relation which becomes 'our house' or 'home'. Ingold calls this process inversion (2011: 70). Inversion, Ingold declares, is the manner in which 'the field of involvement of ... a thing or a person, is converted into an interior schema' and 'reconfigured as the outward expression of an inner design' (2011: 68). In this process things and beings acquire boundaries and are presented as having essential features which do not change even as they engage in new relations. Needless to say this is anathema; for Ingold the relations are always primary and any attempt to categorise relations into particular entities must always emerge out of the on-going relations rather than prefiguring them. Similarly, he bemoans categorisation, seeing this as a process equivalent to inversion, one that prioritises current form over the on-going relations that constitute the object (Ingold, 2011: chapter 13).

We argue that the entities we study are real and bounded, but that this is not merely the outcome of a process of inversion. Further, the process of inversion is itself a mode of engagement that plays a part in shaping material things. The pots, axes, tombs and graves archaeologists uncover stem from relationships that were repeated (never identically, of course), and that repetition gave rise to identifiable types of vessel, such as Beaker pottery (Fowler, 2013, 2014; Jones, 2012). There are realities to such pot typologies because they do not simply bend to will of any archaeologist, but rather emerge through the work of archaeologists and the material, a point Marie Louise Sørensen (1997) has beautifully made. A group of pots of the same type are just as real - and as relational - as any single pot. The same can be said for the vessel type as a category (cf. Marshall and Alberti, 2014: 30). The identification of any pot as a Beaker is a factor of antiquarian and archaeological engagement as much as of prehistoric engagement: indeed, the overall phenomena, the haecceity of the vessel, comprises the constituent media of the vessel, manufacturers, previous pots taken into account during its creation, techniques and gestures, ideas and beliefs, deposition practices, excavation practices, typology as a technique, and so on. The point is that, for archaeologists at least, classification need not separate a thing from its relations, but can rather identify some of the key relations that endure and consider how these play a role in the emerging haecceity of the phenomenon (Fowler, 2013; 2014). We would argue, therefore, that Ingold is wrong to dismiss the importance of actual entities and to solely emphasise the changing nature of relations. Additionally, it seems to us that Ingold's reading of Latour avoids the very aspects of the latter's philosophy that chime with Ingold's own in order to emphasise the differences. His denial of the relational element in Latour's networks ignores important aspects of the latter's position (as well as implicitly disregarding Latour's debt to Whitehead). Ingold is far 
from alone in emphasising this aspect of Latour's philosophy, but it remains the case that this does not do justice to the manner in which Latour too celebrates relations (Fowler, 2013: 30 5, 43-6; Harris, 2013).

\section{Harman's Latour inspires an 'object-oriented philosophy'}

In contrast, for Harman, Latour is a philosopher of relations all the way down. In this version of events, nothing precedes relations and any entity is defined in terms of its current relations only. For Harman's Latour, any change in the relationships that make up an entity result in the production of a new entity. Thus for Harman's Latour the concreteness of actors is totally defined at any one particular moment (Harman, 2009: 80; cf. Pyyhtinen and Tamminen, 2011: 144). Harman, though deeply appreciative of this Latour, is nonetheless critical of specific aspects of his thought. Most notably, whilst he recognises that relations have a role to play, Harman insists that objects always retain something of themselves, in effect they have a particular essence. Harman's essence is not defined as a material substrate, a physical template, or an ideal form; it is not eternal and unchanging and does not have naturally fixed properties (Harman, 2010: 163-4). For Harman, the essence of a thing is that which cannot be subtracted from it without the thing ceasing to exist.

Harman critiques Latour's approach as privileging the current relations in which each entity is situated, above the enduring essence of that entity. He defines the 'relationism' that he opposes as the notion that a 'thing is defined solely by its effects and alliances' (Harman, 2009: 75; cf. Harman, 2011a).

... the object is deeper than any possible relations to it. ... If there is nothing other than its current relations, then why would it ever change those relations? If I am completely exhausted by my current state of relations to all the entities in the world, then there is nothing hidden in reserve, nothing cryptic, nothing that would later unfold and give me the chance to have new relations to things. So in a way this position doesn't do justice to my future. And in a way it can't even explain my present, because we can imagine a counter-factual situation in which other people would be sitting in this room who aren't currently here, who would be seeing me from different angles and having different reactions to me than any of you do. And they would still be reacting to me, not to your relations to me. So there is something here that is really me that these people 
are all encountering. I am not just the sum total of all the ways that I relate to all of you right now. (Harman in Latour et al., 2011: 37, original emphasis).

The problem with this is that Harman overlooks his past as he appeals to the future: he does not account for the historic relations that have comprised him and continue to do so. From Harman's philosophical perspective relations do not accumulate or adhere, but rather come and go with little trace on Harman's essential being. In our view, it is neither helpful to appeal to a modified concept of essences nor sufficient to declare that relations only exist in the present. This does not do justice to the way in which certain kinds of relations affect us enduringly through time - such as the gravitational relationship between the earth and Harman's body. Instead, as archaeologists, we are continually reminded that past relations endure, and past things persist because of continuing relationships and the lingering effects of past relationships: in fact, we would argue, while some aspects of the present may become absent, the past endures (cf. Fowler, 2014). The 'me' Harman discusses above is relational and historical because it is the outcome of a whole set of past circumstances that run over different timespans (parents meeting, the history of human evolution, the origins of the universe). Because he opposes any sense of future states lurking 'in potentia' in an object's relations (for Harman the potential lies in the thing in itself) he argues that Latour requires everything to be constructed in the moment (Harman, 2009). However the effects of Harman's parents' relationship — he and his siblings - demonstrably persist through time. It is not merely Harman that continues to exist, so do some of the relations of which he is an outcome. At one level it might be argued that we are actually discussing the on-going effects of a relationship; Harman's parents might divorce or die, their relationship might appear to end but he, in part an effect of their relations, would not cease to exist. This is a question of scale, however, because within Harman's cells the genetic code formed from both parents continues to produce proteins and allow him to function. A relation between his parents (though clearly not all relations between his parents) endures within his cells. What Harman describes as his essence, we would describe then as relations that cannot be extracted from Harman.

But to further respond to Harman's object-oriented philosophy, and his notion of essence especially, we would argue that it is impossible to remove all relations from any entity. The reason why certain features of the entity endure while many relations in which it is suspended and of which it consists change, is because many other relations are continuing to affect the 
entity in a similar way, or the same ways, as they did in the past. Thus, Harman might justly argue that if we shot him into space then gravity would no longer adhere to him, yet he would exist just the same. However, there are many other forces and relations in effect from the electromagnetic force holding his atoms together to the circulation of blood through his cardiovascular system-even if this is now supported by the operations of a space-suit. Further, we would argue that Harman is historical: he has a past, and it is that past that makes him what he is now. If we remove all these relations we are not left with the essence of Harman; we have nothing. This said, Harman raises an important point about the efficacy of objects as objects, and forces us to account for when shifting relations produce a definitive change in any given object and when they do not. We will return to the importance of treating things as particular entities that relate below.

\section{Will the real Latour please stand up?}

So which of these conceptions captures the reality of Latour's philosophy? The answer is both of them. Latour writes both about real entities that enter relations and how these entities themselves are constituted from relations. This paradox for us is a useful one (as Harman also recognises (Harman in Latour et al., 2011: 29)). We need a theory of relations that allows us to recognise entities which are at times bounded and distinct, but also explore how these entities are themselves relational. It is here that we differ from other archaeologists who have recently engaged in this debate (e.g. Olsen 2010; Olsen et al., 2012; Witmore 2012) who wish to link a theory of relations to a notion of a non-relational withdrawn essence of the kind hypothesised by Harman. For Latour, the world is not made up of fact and fiction, but rather the existence of all manner of entities, human and non-human, defined by their relations. Thus fictional characters are no less real, nor are ideas less real, than historical figures and material things. In contrast to Ingold, therefore, we cannot take entities or categories (Ingold's inversions) to be less real than the relations that make them up. Inversion, and more broadly the translation of becoming into being, is surely a part of the real history of relational existence. Once entities have been identified as such they have a real, transformed, role to play in the development of history. As Latour emphasises, the fact they are created does not make them less real than the relations that constitute them: just because something is fabricated does not make it false (Latour, 1999: 115). Latour is not concerned with accurately representing reality, but with translating reality through productive interaction with real entities, each of which is fabricated through various previous translations. 
What we require then, is an approach that allows us to consider how both sides of this tension emerge without arguing that either webs of relations or bounded entities - neither becoming nor being - are primary, and that places the work involved in translating entities and relations at the forefront. We suggest that one such approach can be found in the works of Karen Barad.

\section{Rethinking relations: Waves, particles and indeterminacy}

Karen Barad $(2003,2007)$ has investigated the recognition of relational entities in quantum physics, particularly drawing on the work of early twentieth century Danish physicist Niels Bohr ${ }^{\text {iii }}$. Barad (following Haraway, 1992, 1997) proposes a 'diffractive methodology' based on an appreciation of the physics of waves. Waves are disturbances in media, and two waves can occupy the same space at the same time, which two particles cannot. When waves intersect they are diffracted 'producing a pattern that results from the relative differences (in amplitude and phase) between the overlapping wave components' (Barad, 2007: 76-7): some features of the interacting waves become amplified and others diminished. For Barad our investigations of the world send out ripples, altering the very things we attend to and diffracting with the waves of other actions. These alter the matter and actions that we study. Barad contrasts this diffractive methodology, focussed on intra-actions ${ }^{\text {iv }}$ within the object of study, with a 'reflective' approach which relies on 'reflecting on representations' (Barad, 2007: 89-90), looking from the outside at an object assumed to pre-exist our enquiry. For Barad, even avowedly reflexive approaches are problematic because they perceive an object of study as representing something and as a priori detached from the study itself. In contrast, Barad aims to produce a methodology which acknowledges that an entity is what it is because of the precise configuration of relations that comprise it at any moment (ibid.: 91), and recognises the place of the investigator as part of that configuration. Relations are not just within the object of study but all around it, pervading it and constituting it: an entity is 'entangled' among and inseparable from the various apparatus, circumstances, theories and participants in that moment. In fact, the most salient entity here is the overall 'entanglement' itself: that, she suggests, is the real object of study. The entities that Barad considers are atoms and electrons, and emerge only when certain apparatus (from photographic plates to ideas such as that energy exists as 'quanta' or packets at various scales) is brought to bear in particular arrangements. To extend this to our earlier example, Harman is not best considered as a distinct monadic entity, but as an entanglement, as part of other phenomena on which he 
relies for his existence and which specify him in certain ways: Harman the academic, for instance.

Here we would like to draw on one of Barad's examples to frame the discussion of relational entities and entities in relationships: the indeterminate nature of electrons. Barad (2007: 97121) describes how light can be measured using apparatus set up to record the presence of waves, or apparatus configured to record the passage of particles, and explains that electrons can also be measured to exist as waves or as particles. As Barad (2007: 298) informs us, '[p]articles are objects that are localised in space, whereas waves are disturbances that are spread out in space'. However, an electron cannot be demonstrated to be a wave and a particle at the same time: its state outside of any given experiment is indeterminate. In quantum physics, Barad (2003: 814) states, apparatus can be devised to measure the momentum of passing electrons, in which case they are shown to move in waves, or the position of an electron, in which case it appears as a particle, but not both. Following Bohr, she stresses that

...theoretical concepts - like position, momentum, space, time, energy, causality, observation and particle and wave - that classical physics takes for granted need to be properly understood as idealizations or abstractions; in the absence of appropriate experimental arrangements, concepts do not have determinate meanings. (Barad, 2007: 296).

In other words, ideas and theories work only when reality is configured to allow them to do so; they are and rely on 'actual physical arrangements' (Barad, 2003: 820) of electrons, photographic plates, physicists, and so on. Ultimately, Bohr was able to demonstrate that an electron is an entity that appears at the boundary between wave and particle in classical physics: it can have wavelength or position, but it cannot have both (or, more accurately, 'one can to a degree define both the position and momentum simultaneously, but not both sharply at once' (Barad, 2007: 304, her emphases)). In this, Bohr's entanglement demonstrates the complementary or exclusive nature of energy and time, or position and momentum, and the fact that energy shades into time, and position into momentum, at an indeterminate level (ibid.: 300). In parallel with this, we would contend that we can apprehend relational becoming and beings that relate 'but not both sharply at once': we can modulate between the two to useful effect by reconfiguring the assemblages in which we are situated. Furthermore, 
as a result of any engagement new possibilities for further engagement arise, presenting opportunities for new propositions and thus new questions, new indeterminacies. Phenomena can be 'first determined and then made to be indeterminate once more through an appropriate modification of the apparatus' (Barad, 2007: 316).

We contend that Barad's conclusions about the relationship between theories, apparatus, the objects of study, the student and the overall entanglement of each in any resulting entity, hold for all fields of study. Importantly, this does not mean that what we are studying will show up to be whatever we look for: electrons may be waves or particles, but this does not mean they could be anything. Neither is this the same as a relativist position in which interpretation is a matter of perspective: interpretation is rather a matter of work and configuration. New work reconfigures reality, whether that work is considered 'theoretical' or 'practical' in tenor.

In the remainder of the paper we will retain the wave, the particle and the indeterminate entity as modes or configurations of material engagement - not because we think these terms should replace others currently at work in understanding the world in a relational way, but to temporarily focus on the work involved in modulating between becoming and being. We will use the term wave to refer to the unfolding becoming of the object of our study; this is a diffracting wave resulting from our interaction with other forces within the phenomena under investigation. The intersecting waves diffract, or change direction and wavelength, when they overlap, forming new waves. We will use the term particle to refer to the object of our study as an entity configured in a differing way due to changes in the configuration of the overall entanglement or assemblage: 'being' highlighted at a certain point in 'becoming' due to a certain analytical technique. Particles have a definable mass, extent and position. The phenomena or assemblages we study are what they are-in the case mentioned at the start of the article and returned to below, a Neolithic chambered tomb-but what we want to explore is how such a phenomenon is at once historically unfolding and also a distinct entity, albeit particularised at a greater scale than we might conventionally think. We cannot study an object as both a particle and a wave at once, at least 'not both sharply at once'. However, we can shift from studying the particularity of an entity to studying how it is unfolding as a wave or line that is becoming, acknowledging that the phenomena changes in the process of this shift. Furthermore, such shifts generally occur as new questions are asked and new research conducted. 
This reading of Barad resolves the question of whether we start with real objects that enter into relationships, or whether we should begin with relationships that are only abstracted, later, into bounded objects. Not only does she reveal that neither is primary, she also shows how both are relational. Thus no appeal to essence is required.

What is also needed, however, is an appreciation of the history of the entities producing relations and entities emerging from relations; precise histories for all the elements in the phenomenon. What we require, therefore, is an approach capable of dealing with both episodes of being and the dynamics of becoming, and one that reveals the work required to reveal either configuration (cf. Jones, 2012). In attempting to appreciate the way that relations endure even as an assemblage changes we need to turn elsewhere. This is because each of the experiments Barad describes focuses on a new electron each time. Each electron in turn is defined as either a wave or particle but the same electron is not studied twice. Yet as we have stressed, material things such as West Kennet endure over the long term. Therefore we need to couple Barad's ideas to analyses of how enduring things change.

One area of Latour's scholarship that deals explicitly with change is the circulating reference, an idea already popular with some archaeologists (e.g. Olsen et al., 2012; Witmore, 2007, 2012). Latour $(1999,69-79)$ argues that each time an entity is studied some of its properties are translated into new entities. These entities become chained together: they are transformations in matter and form but linked by the properties they share:

Phenomena ... are not found at the meeting point between things and the forms of the human mind: phenomena are what circulate all along the reversible chain of transformations, at each step losing some properties to gain others... (Latour, 1999: 71 , original emphases $)^{\mathrm{v}}$.

In a classic example, Latour (1999) traces the movement of soil first from the Amazon rainforest to laboratories and then through a series of translations, during which the soil is coded, analysed and inscribed. The soil here is capable of being transported across the world and redescribed on countless charts and graphs. Each new description, each translation, amplifies certain properties of the soil enabling those properties to circulate further, but also reduces other features of that soil: its ability to support life recedes even as its ability to engage in scientific description increases. In the terms we are using, the waves encapsulated in specific lumps of soil become diffracted, and the sampled soil becomes particularised in 
new ways. The result is an expanding and diversifying, productive phenomenon, yielding new 'waves' and new 'particles' sequentially — indeed the visual similarity between Latour's diagrams for circulating reference and the peaks and troughs of waves, along with his use of the terms 'amplify' and 'reduce' show close affinities with the study of diffracting waves (Latour, 1999: fig. 2.21).

We would present a reading of Latour's circulating reference ${ }^{\mathrm{vi}}$ emphasizing that some features of an entity endure through the process of translation while others are reduced: this provides a temporal and sequential dimension, a 'chain of transformations'. The 'reference' is at once a relationship (e.g. the relations among soil, worms, trees and grass, tins, colour charts and maps) and a particular entity (a region of land either side of the boundary between rainforest and savannah), and through different operations in the sequence may be demonstrated as either or both. This is precisely what we intend by considering the wave/particle proposition (and the unknown, the answer to the research question, is initially indeterminate). Using these concepts allows us to begin to perceive the historical nature of a phenomena and how it is changed through its interaction with other entities and new relationships. Rather than the essence of a single object (say, a bag of soil) that Harman would see as providing a passage through time, it is the history of transformation of the overall phenomenon (the forest-savannah boundary) that allows us to comprehend the passage of time. Importantly, the translations change some of the relations within a phenomenon but not all of them at the same time, meaning we can trace both historical change and continuity without appealing to the essence of the thing ${ }^{\mathrm{vii}}$. Any feature of the circulating reference may be amplified or reduced in each interaction, and any of those features that are so affected can be understood as waves that have diffracted. The resulting wave (the 'new' reference) is different than those colliding in its creation, but has its roots in each and extends certain key features of those waves (e.g. the colour of a specific sample of soil and the practice of identifying soil colour). The resulting wave may be diffracted in further interactions.

So far we have combined the idea of a phenomenon as a unique assemblage of factors with the concept of the circulating reference. This combination of approaches allows for a methodology by which we can study the historicity of a phenomenon without reducing time to a series of moments or separating out the act of investigation from the phenomenon investigated. Fundamentally this allows us to discuss the ever emergent and relational 
qualities of phenomena in a given configuration of reality, whilst also recognising how these properties last through time as some features of that articulation endure while others change. From this basis, there is no need to appeal to essences in order to explain the enduring features of phenomena. Moments of particularization emerge alongside the vibrant motions of waves or lines in the relational and interactive process of becoming. In the second part of this article we explore this approach through an archaeological example; the phenomenon that is West Kennet Neolithic chambered tomb. We do this to highlight both the differences and similarities between a chambered tomb as an object of study and electrons or soil samples. A chambered tomb is physically located in a single place as could be said for the strip of land at the edge of the rain forest in Latour's example, and contents and soils have been removed through excavation (as with those of the rain forest boundary); it can be appreciated as like a wave or a particle through different apparatus, just as an electron can be, but very unlike an electron the same tomb, rather than a different but identical tomb, is subjected to differing apparatus in a series of successive intra-actions. It falls, then, to an appreciation of something that endures over time, like this tomb, to move forward the theoretical work needed to resolve the question of how relational entities endure.

\section{Enduring relations and relationships with effects at West Kennet chambered tomb}

We begin with the construction of West Kennet and follow its history through to the most recent interventions into its dating and use-life. As we move through time we become increasingly aware of the multitude of actors caught up with it. As with Latour's circulating reference, and in parallel to 'symmetrical archaeology' viii, we trace this study 'from the middle outwards' in that what we say about the beginning of the site is inseparable from engagements that come millennia later. That said, West Kennet exists and existed throughout the narrative as a real entity in other engagements long before archaeologists were involved. We present the discussion initially as a chronological sequence in order to draw out moments of increasing intensity of engagements in the more recent past, and their entanglement within what we know about the more distant past.

We do not claim that what follows is comprehensive. Rather it traces one particular set of interventions and translations that we can tell are significant in the history of the site. We cannot cover all the archaeological citations of this monument, let alone the countless encounters that take place there every year. Whilst our narrative begins in the Neolithic we 
are interested in tracing how West Kennet circulates and how diffractions alter it, as well as how it repeatedly becomes particularised, and for that reason we will only cite academic references for information at the point when they enter the narrative even though our narrative consists of information derived from these sources. Having set out this history we will examine the ways in which archaeological work can transform the indeterminacy of West Kennet into a set of traceable relationships (a diffracted wave), as a bounded and localisable entity (a particle), and indeed as the indeterminacy that precedes the identification of either of these two states.

The stones at West Kennet were erected through significant effort uniting bodies, ideas, stones, chalk and earth. Holes were dug into which large sarsen orthostats were placed, propped up as dry-stone walls were erected around them to create a contained space and prevent the soil, which was being dumped to form the surrounding mound, from leaking into the tomb. At least two orthostats had stone axes polished against them prior to their incorporation in the monument, and some of the stones used in the dry stone walling had been brought at least $20 \mathrm{~km}$ to the site. Capstones were dragged up over the earthen mound and carefully manoeuvred into place above the chambers. When the initial construction was at an end there was a long earthen mound containing a stone passage at the eastern end with two chambers at either side of this passage and one at the rear. These spaces permitted performances in the forecourt, within the passage, and in the various chambers. Some of these performances were rites of passage, including rituals surrounding the transformation of the dead.

At least 36 corpses were brought into the structure, probably laid successively in each of the chambers, over less than 30 years. Selection and placement of the dead was specific, so that, for instance, all of the very youngest children were deposited in the south-east chamber along with a man and a woman. As the dead entered the tomb they became separated from the community of the living, and came to join a community of the dead. The technologies of the time, such as pottery, allowed people to draw a connection between bodies, pots and the monument itself. Each was a kind of body; each was a kind of vessel. The tomb contained the bodies of the dead, and eventually only their bones. These materials had the capacity to engage with people and evoke meaning and emotional resonance - they were potent. These materials included the stuff of the ancestors, passed down from one generation to another, from one vessel to another. 
After a period of possible disuse, around 100 years after the last burial, people brought chalk blocks, sarsen rubble and earth into the tomb, and the dry stone walling between some of the orthostats collapsed. During the period between the insertion of the first body and the introduction of the rubble and debris, people entering the chambers disturbed the bones of the dead. Some of this disturbance included deliberate re-arrangement of bones, resulting in, for example, a cache of vertebrae against the northeast corner of the north-west chamber. This activity ended with the partial blocking of the south-west and north-west chambers with sarsen stones which prevented easy entry but not access to the chambers as they did not reach the ceiling.

But the site did not cease to be used as a tomb. The bodies of five infants were placed successively in the south-east chamber as the monument was used intermittently and filled with earth and rubble over many generations. Interleaved with the earth and rubble throughout the tomb were sherds of pottery (some seemingly resulting from the smashing of vessels in the forecourt), flint arrowheads, knives and scrapers, whetstones, bone scoops, pins and beads, beads made of shell or of stone and boar tusks amongst other things. At the top of the accumulating infill the body of a goat was placed in the north-west chamber. By this time the chamber was almost filled with chalk rubble, leaving little room for manoeuvre beneath the capstone roof. When the passage and chambers were packed with material to this extent the facade of the tomb was dramatically altered. Four massive sarsen stones were brought to the forecourt at the entrance of the passage, people with antler picks dug holes to provide sockets and the stones were erected with their broad edges facing outwards to the east and providing a blocking wall across the front of the tomb. The forecourt area was packed with sarsen boulders, and three more monoliths were raised to provide a flat facade to the eastern end of the site. At this point the relic materials (human bone, beads, potsherds and so on) were stoppered in the monument.

In subsequent centuries the barrow continued to make an impact on the world through its place in the landscape, and the way it was circulated through stories and myths, but these did not transform the physical structure of the monument. Stones, earth and chalk lay in much the same relation with one another over a long time, shifting gradually or in small events, such as in the burrowing of animals. In the seventeenth century AD the tomb was dug into several times both on the south side and around the entrance of the tomb on the east side. The 
excavators left behind clay pipes and moved sherds of prehistoric and Roman pot. It is most likely that a local doctor, Dr. Toope, was digging in the tomb to secure human remains to turn them into a popular medicine. In 1723-4 the barrow was drawn and described by the antiquarian William Stukely who published his findings in 1742, labelling the tomb an 'ArchDruid's barrow'. The barrow saw further engagements as people in the eighteenth and nineteenth centuries dug into it for flint and chalk and cut a wagon road through the middle.

In 1859 John Thurnam excavated at the site, notably towards the eastern end of the barrow, removing fills from part of the passage and the west chamber including six burials, four of which were articulated. This was done in a manner designed to avoid moving the large capstones, but plans were foiled when a three-tonne monolith plunged into the void left by their diggings. The smaller sarsen stones that had blocked off the south-west and north-west chambers at the end of their primary use fooled Thurnam into believing there was only a single chamber in the mound, and he left the others untouched. Following the Act of Parliament setting up a schedule of ancient monuments in 1882, West Kennet became the second monument on the list on the $13^{\text {th }}$ of August 1883 . The tomb was now legally protected from unlicensed digging.

In 1953 Stuart Piggott was invited to excavate the site, "with a view to subsequent conservation as a site under guardianship' (Piggott, 1962: ix). In 1955 Piggott and Richard Atkinson began their excavations. In 1962, Piggott published the result of their excavations, and of his research into the 'the West Kennet long barrow'. It is Piggott who provides the information on activities at West Kennet during the historical period which we have related above. He also provided the fundamental structural details of the monument and published accurate measurements of the extent of the tomb (see fig. 1) and the position of the primary human remains (see fig. 2), in this report and the earlier interim statement (Piggott 1958, 1962). Piggott used pottery typologies originating in the work of nineteenth century scholars to provide a relative chronology of the site and establish that it was constructed during the Neolithic period. Piggott's publication provided a state of the art archaeological report into the monument. Following the excavations the monument was consolidated and conserved, becoming an open visitor attraction, and also entering the public imagination through television programmes and other mass media. Once more people travelled to see West Kennet. The materials removed during excavation were transferred to different locations for 
analysis before being deposited at museums and laboratories in Devizes, Cambridge and Edinburgh (Piggott, 1962: x).

Figure 1: Plan of the West Kennet Long Barrow (after Piggott, 1962, fig. 2)

Figure 2: Plan of the chambers with position of primary interments (after Piggott, 1962, fig. 8)

Although the tomb has not seen any further excavation, it has continued to intertwine with archaeologists' understandings of the past and play an important role in interpretations of the Neolithic in Britain. For instance, in the 1980s Julian Thomas and Alasdair Whittle (Thomas and Whittle, 1986) published a reanalysis of the tomb's contents, arguing that in the earliest phase bodies were deposited intermittently over a long period, and were reduced to bones which were circulated because they were associated with ancestral fertility. In the same year the first radiocarbon dates for the monument were also released, locating the activity that had taken place there to between 3600 and 3380 cal BC (Gowlett et al., 1986). Later, in 2007 Alex Bayliss, Alasdair Whittle and Michael Wysocki made a significant impact by re-dating the tomb and modelling those dates using Bayesian statistics (Bayliss et al., 2007). This revealed that the initial use of the tomb had been brief, with burials taking place for less than 30 years or so between 3670 and $3635 \mathrm{cal} \mathrm{BC}$, followed by a slow accumulation of deposits over the next millennium, including the burial of infants in the south-east chamber sporadically after c. 3300 cal BC. As part of a wider re-dating of Neolithic monuments, West Kennet contributed to a transformed history of the fourth millennium BC in Britain.

There are many more ideas, influential actants, that have shaped our articulation of West Kennet, for instance the influx of concepts into prehistoric archaeology from anthropology (e.g. Barrett, 1988) and philosophy (e.g. Thomas, 2002; Tilley, 1994), but also theories developed within archaeology (e.g. McFadyen, 2007). Although our intention is not to produce new archaeological knowledge about the site, this article is now a small part of the reference that circulates: our ideas and interpretative techniques are factored in to the extending assemblage, the expanding phenomenon, that is 'West Kennet long barrow'.

\section{West Kennet as a wave}

Recognising West Kennet as a wave, a diffraction of different contributing waves with many points of origin, involves tracing the unfolding histories of the different human and nonhuman actors entwined in the narrative above. It involves the work of recognising the 
multitude of different and changing relations that constituted the monument through time. Through its construction the histories of different materials became bound together, as did the materials themselves: earth and stone of different kinds including chalk. Some of these came from far away; as West Kennet was built waves emanating from other places diffracted, forming and transforming the wave that is the site. Soon after, human bodies entered the tomb, their histories reforming the wave at West Kennet. Over a thousand years of activity in the chambers and passage, involving pots, people, things and animals - each with differing connections, relations and histories - changed the character of the West Kennet wave: its amplitude and wavelength, its resonance at that moment, that particular arrangement and event. At the same time, those interactions caused the wave to diffract, producing new waves travelling in new directions and media. For instance, when Piggott and Atkinson excavated in 1955 and 1956 they took photographs and made drawings of the tomb that passed on to have other impacts. Piggott too became part of the repeatedly transforming, vibrant West Kennet wave, as had figures like Toope, Stukely and Thurnam before him.

In each case some of these encounters affected the wave at West Kennet more significantly than others. The quotidian impact of visiting tourists may have relatively little enduring impact in comparison with the more significant additions made by Piggott, his team, the associated agencies and apparatus (particularly, in this respect, their place in reconstructing the monument). The after-effects of Piggott's excavations changed the course and strength of the wave allowing us to trace it in new ways. We have already noted the manner in which photographs and drawings of the site diffracted, allowing features of West Kennet's wave to pass into new spaces. The physical removal of the finds also illustrates the diffraction of West Kennet's wave. The histories of the bones from lab, to museum, to lab, to radiocarbon facility, reveal how the wave of West Kennet can disperse itself into multiple physical locations, and interweave with new apparatus to produce new assemblages - similar to the circulating reference of the rain forest soil discussed by Latour (cf. Lucas, 2012: chapter 6). These histories are still part of the West Kennet wave, even as they diffracted it, and diffract the waves of others.

The wave 'West Kennet long barrow' has become a circulating reference, able to move into multiple narratives through its translation into photographs, find reports, websites and radiocarbon dates. Such circulation induces changes in the wave 'as a whole', even when it apparently leaves 'the material' that would be conventionally identified as the tomb the same: 
there are material effects, however, to taking a photograph, producing new radiocarbon dates or new Bayesian models for site chronology. The wave moves well beyond the vicinity of the tomb, into books and lectures theatres and websites. Certain interactions will change the character of the wave: for example, the production by Bayliss et al. (2007) of the Bayesianmodelled dating for the activity at West Kennet both diffracts the wave and also changes its wavelength and amplitude in that the previous character of the wave related to the age of the site has been diffracted. The material trace of that older wave still exists and will endure (for instance in older texts about the site), but it has been diffracted away from our narrative of the site and its future impact has radically diminished: it has lost its resonance as the world around it has changed. Indeed, it becomes more and more apparent as a particle; a 'product of its time' and an enduring residual legacy of a particular interaction in a specific entanglement (cf. Hodder, 2012, 193-5). It used to articulate well with the narrative before the 2000s, but no longer does. Bayliss et al.'s work has not changed when West Kennet was built, but it has changed what West Kennet can do in narratives about the Neolithic; new affective properties of West Kennet have emerged.

\section{West Kennet as a particle}

However, in order to be invoked in archaeological narratives (or, indeed, prehistoric narratives), West Kennet is also particularised; that is, it is defined as a bounded entity. This takes many forms, including the reconstruction of the chambers, passage and façade now accessible to the public, Piggott's excavation report, and the results of the chronological modelling. Particularisation is the process by which distinct entities emerge, subsuming the relations from which they are constituted into a black box (Latour, 1999) as they act in the world with new ontological weight. It is the moment that West Kennet becomes not just a collection of earth, chalk, stone and bone but a tomb. This moment, this historical engagement, allows West Kennet to persist as a tomb, as something that can potentially be repeatedly identified as a tomb in successive intra-actions, subsequent particularisations, even when it has ceased to be used to bury the dead ${ }^{\text {ix }}$. This does not mean that the relational property of being a tomb was important in all later relationships with West Kennet, but it is instrumental in many of those later relationships. In later times West Kennet was particularised in new ways, by Stukely's drawings in 1723 and 1724, when it became a scheduled ancient monument in 1883 , its name 'West Kennet' no longer a matter of local legend but legal nicety. When Piggott dug and described the site, it became more than simply an ancient place or an 'Arch-Druid's barrow' but a Neolithic chambered tomb. The 
radiocarbon programme, the evaluation and re-recording of human remains, the Bayesian modelling of radiocarbon dates, all of these particularise West Kennet in a new way, it gives the very words 'West Kennet' new meaning. Claims that Neolithic tombs were always in use for centuries in their primary phase can now simply be challenged by saying 'but what about West Kennet?'.

\section{West Kennet as indeterminate}

It is not possible to grasp the indeterminacies involved in the emergence of West Kennet sharply. This remains largely offstage, as whenever we focus on the narrative we produce, we involve the indeterminate in the production of either a wave or a particle; a path, becoming, or process, or an entity, place or thing. Yet exactly what is indeterminate about the site has changed through the sequence of interactions that have formed and transformed West Kennet. Initially, the form and composition of the tomb were indeterminate and were determined during its construction, for instance. The stones, chalk and earth brought to this place to be combined in building West Kennet were all features of its indeterminacy that through the act of construction became involved in the emerging wave and/or particle of West Kennet. As new apparatus, new theoretical concepts and questions, became possible in relation to West Kennet, so new indeterminacies arose: how old was West Kennet in calibrated radiocarbon years? Over what length of time were the chambers used to deposit remains of the dead? Since these questions have been answered (for now, and to varying degrees of precision), the results are determined - but as new apparatus becomes available, new engagements can be proposed, so those results fall back into being indeterminate: new research could now provide a different answer (cf. Marshall and Alberti, 2014). But there is a further point: what is indeterminate depends on the scale of the phenomenon. Thus, during the first millennium AD when human remains lay undisturbed and unknown in the tomb, West Kennet was not determined as a tomb by human beings living in the landscape around it. However, if we scale down to consider the relations among the bones, soil, chalk and stones, it is clear that certain relations among these elements persisted, with some aspects of those relations changing gradually, over long periods of time. These enduring relations allowed the tomb to be identified as such centuries later -although the concept of 'tomb' in twentieth century Britain arguably configured West Kennet in quite a different way to how it was configured in the Neolithic. 


\section{Conclusion}

We started this paper by asking how we can best understand a Neolithic chambered tomb such as West Kennet. Is it a singular entity or a set of relationships? To appreciate the history of a material phenomenon such as West Kennet we need to attend to both of these elements. Our work with the site involves us understanding both how it can be configured as an assemblage always in becoming, and yet also be studied as a thing in its own right. We need to trace both the changing relations that transform the monument through time and those that persist allowing it to retain recognisable form. For us, each reconfiguration of reality around and including West Kennet allows some existing relations to continue as well as transforming some or adding others. Some of these engagements are diffractions that change the way that West Kennet is becoming, which we have described as a wave, while others show up West Kennet as something that can be particularised and is effective as a bounded entity. Working with relations and entities involves repeatedly reconfiguring the assemblage of apparatus, materials, ideas, human beings (dead and alive), and so on. Thus, Ingold is not wrong to identify the process of inversion by which entangled lines become things, but is mistaken to argue that this process is an erroneous way to appreciate phenomena: we would argue that it is important to appreciate this as an example of how certain aspects of material phenomena emerge in specific intra-actions. Alongside this we have identified the indeterminate state of any aspect of the site prior to our engagement with it. The relations among the balanced stones within the tomb persist and keep the structure standing, but if we wish to produce a two or three-dimensional plan of exactly how they rest on one another excavation is needed, reconfiguring the assemblage, determining the extent of those previous relationships in a way that fixes them at a certain moment and produces new relationships through new media that be carried into new arenas of activity.

This approach should not be read to argue that there are only two ways that enduring material things can be appreciated - as waves or particles - but rather that there are multiple ways that material things are reconfigured through successive configurations of apparatus. Things are always both being and becoming, but in many different ways, and specific configurations of reality alter what those things are and what they can become. Studying material things is thus about recognising both the reality of their particularisation at specific moments, as well as about tracing flows of relations.. We cannot understand the complexity of the "worlds of materials' (sensu Ingold, 2011: 31) if we insist that only one mode of analysis is appropriate: 
modulating between modes - continually reconfiguring phenomena in varying ways - is vital to exploring what things are and can be. Working across different scales is also vital. Contra Harman (2011a) we do not 'undermine' West Kennet if we focus on how certain physical forces keep the mound together or on the decay of radioactive atoms within the human bones from the tomb, nor do we 'overmine' it by considering the impact it now has on our accounts of the early Neolithic period, provided we move between these and other scales. Importantly, both scale and the modes in which material things appear, are emergent from the engagement, from bringing ideas, techniques and equipment to bear in intra-acting with the site, within its unfolding and changeable history. The temporal, material world is complex and we need more than a single means of engagement with it if we are to understand its past and its persistence in the present.

\section{Acknowledgements}

The paper arises from a period of discussion during a Leverhulme Early Career Fellowship for one of us $(\mathrm{OH})$ at Newcastle University. The Trust's generosity in funding the research is gratefully acknowledged. We are also thankful for critical discussions with the Newcastle University Latour reading group, Rachel Crellin, Louise Tolson and Sophie Moore, and with Ben Alberti (CF). Further helpful comments were added by two anonymous reviewers. Any mistakes that continue to circulate are entirely of our own making.

\footnotetext{
${ }^{\mathrm{i}}$ An actant is any entity which can interact with another entity, and for Latour this interaction produces a change in each of the entities involved.

ii This debate is matched by one in philosophy between Graham Harman (2011b) and Steven Shaviro (2011). Shaviro critiques Harman's reliance on essences and argues that a more fully relational approach (drawing on Whitehead rather than Latour) is required. Shaviro in this debate takes a position similar to that of Ingold. ${ }^{i i i}$ Barad is not alone in considering the metaphysics of quantum physics, nor in adopting the view that phenomena occur how they do relationally: in particular, Michael Epperson adopts a 'relational realist' perspective on quantum mechanics drawing on the philosophy of Alfred North Whitehead (e.g., Epperson, 2009). Epperson's (2009: 361-2, original emphasis) conclusion that "the essence of "being" is "becoming", and the actual occasion is the fundamental, "substantial" unit of becoming ... [e] ach actual occasion is thus fundamentally a unit of relation' is parallel to the conclusion we reach here, with the 'actual occasion' being a particularly-configured event or assemblage.

${ }^{\text {iv }}$ Barad uses the term intra-actions to stress that any interactions are really within the overall entanglement: thus, when we describe the electron interacting with the photographic plate, we are really describing an intraaction within the experiment in which the electron and the plate are entangled. For sake of ease we will largely stick with the term interaction, but all of the interactions we describe in this article are intra-actions within the entanglement that involves us and the other participants in the article. The way that any interaction instantly becomes an intra-action and expands the phenomena involved is discussed further by Fowler $(2013,2014)$.

' It is worth noting here that Latour is contrasting 'between' and 'along' in precisely the same manner as Ingold does in his critique of Latour discussed above.

vi One reviewer pointed out that Latour's model highlights the gaps between media in each act of translation, and that these gaps denote that each entity is distinct (cf. Witmore, 2007: 551). Certainly, Latour's model is not arguing that a record of the colour of the soil is the same entity as the lump of soil in the sample tin. However, we would emphasise that 'phenomena' (e.g. the forest-savannah boundary) circulate in this scheme and key
} 
features of the soil pertaining to such phenomena are effectively extended as these circulate in the translations of form and matter that Latour studies. It is our translation of Latour's concept that entities are therefore extended through this process: as features of entities circulate, so those entities - now transformed - expand and interpenetrate other entities.

vii This position has close affinity with Lucas' (2012: 187) reading of Whitehead where stable entities or enduring objects are networks of 'more basic, momentary events' or actual occasions. We would argue that the length of a 'moment' or 'occasion' in this sense can be highly varied given that some relations persist over the very long term.

viii Olsen et al (2012: 161-71) explore a broadly contemporary British Neolithic mortuary structure and earthen long barrow at Fussell's Lodge, starting with the details of the excavation and site report and examining how its discovery and repeated interpretation has contributed to revisions in understanding the British Neolithic. Both our project and theirs focus on similar sites and the role of both remains and archaeological activity in the engagement, but our account is explicitly directed towards drawing out modulations in engagement over the long term.

ix This recognition of persistence diverges from Barad, and archaeologists who have employed her work (e.g. Marshall and Alberti, 2014).

\section{References}

Alberti, B. \& Marshall, Y. (2009) 'Animating Archaeology: Local Theories and Conceptually Open-Ended Methodologies', Cambridge Archaeological Journal 19: 344-56.

Barad, K. (2003) 'Posthumanist Performativity: How Matter Comes to Matter', Signs: Journal of Women in Culture and Society 28: 801-31.

Barad, K. (2007) Meeting the Universe Halfway: Quantum Physics and the Entanglement of Matter and Meaning. Durham (NC): Duke University Press.

Barrett, J.C. (1988) 'The Living, the Dead and the Ancestors: Neolithic and Early Bronze Age Mortuary Practices', in J.C. Barrett \& I. Kinnes (eds) The Archaeology of Context in the Neolithic and Bronze Age: Recent Trends, pp. 30-41. Sheffield: J. R. Collis.

Bayliss, A., Whittle, A. \& Wysocki, M. (2007) 'Talking About My Generation: the Date of the West Kennet Long Barrow', Cambridge Archaeological Journal 17: 85-101.

Bennett, J. (2010) Vibrant Matter: a Political Ecology of Things. London: Duke University Press.

Conneller, C. (2011) An Archaeology of Materials: Substantial Transformations in Early Prehistoric Europe. London: Routledge.

Delanda, M. (2006) A New Philosophy of Society: Assemblage Theory and Social Complexity. London: Continuum.

Deleuze, G. \& Guattari, F. (2004) A Thousand Plateaus: Capitalism and Schizophrenia. London: Continuum. 
Edensor, T. (2011) 'Entangled Agencies, Material Networks and Repair in a Building Assemblage: the Mutable Stone of St Ann's Church, Manchester', Transactions of the Institute of British Geographers 36: 238-52.

Epperson, M. (2009) 'Quantum Mechanics and Relational Realism: Logical Causality and Wave Function Collapse', Process Studies 38(2): 339-66.

Fowler, C. (2013) The Emergent Past: A Relational Realist Archaeology of Early Bronze Age Mortuary Practices. Oxford: Oxford University Press.

Fowler, C. (2014) 'Dynamic Assemblages, or; the Past is What Endures: Change and the Duration of Relations', in B. Alberti, A. Jones and J. Pollard (eds) Archaeology After Interpretation: Materials, Relations, Becoming, pp. 235-256. Walnut Creek: Left Coast Press.

Gowlett, J.A.J., Hall, E.T., \& Hedges, R.E.M. (1986) 'The Date of the West Kennet Long Barrow'. Antiquity 60: 143-4.

Haraway, D. 1992. 'The Promises of Monsters: a Regenerative Politics for Inappropriate/d Others', in L. Grossberg, C. Nelson, and P. Treichler (eds) Cultural Studies, pp. 295337. New York: Routledge.

Haraway, D. (1997) Modest_Witness@Second_Millennium.FemaleMan@ _Meets_OncoMouse TM. Feminism and Technoscience. New York: Routledge.

Haraway, D. (2008) When Species Meet. London: University of Minnesota Press.

Harman, G. (2009) Prince of Networks: Bruno Latour and Metaphysics. Melbourne: Re.Press.

Harman, G. (2010) Towards Speculative Realism: Essays and Lectures. Winchester: Zero Books.

Harman, G. (2011a) The Quadruple Object. Winchester: Zero Books.

Harman, G. (2011b) 'Response to Shaviro', in L.Bryant, N. Srnicek and G. Harman (eds) The Speculative Turn: Continental Materialism and Realism, pp. 291-303. Melbourne: Re.press.

Harris, O.J.T. (2013) 'Relational Communities in Prehistoric Britain', in C. Watts (ed) Relational Archaeologies: Humans, Animals, Things, pp. 173-89. London: Routledge.

Harris, O.J.T. (2014) '(Re)assembling Communities', Journal of Archaeological Method and Theory, 21: 76-97.

Hodder, I. (2012) Entanglement: an Archaeology of the Relationships between Humans and Things. Oxford: Wylie-Blackwell. 
Holbraad, M. (2009) 'Ontology, Ethnography, Archaeology: an Afterward on the Ontography of Things', Cambridge Archaeological Journal 19: 431-41.

Ingold, T. (2011) Being Alive: Essays in Movement, Knowledge and Description. London: Routledge.

Jones, A.M. (2012) Prehistoric Materialities: Becoming Material in Prehistoric Britain and Ireland. Oxford: Oxford University Press.

Jones, S. 2010. 'Negotiating Authentic Objects and Authentic Selves: Beyond the Deconstruction of Authenticity', Journal of Material Culture 15: 181-203.

Jones, S. \& Yarrow, T. (2013) 'Crafting Authenticity: an Ethnography of Conservation Practice', Journal of Material Culture 18: 3-26.

Latour, B. (1999) Pandora's Hope: Essays on the Reality of Science Studies. Cambridge (MA): Harvard University Press.

Latour, B., Harman, G. \& Erdélyi, P. (2011) The Prince and the Wolf: Latour and Harman at the LSE. Winchester: Zero Books.

Lucas, G. (2012) Understanding the Archaeological Record. Cambridge: Cambridge University Press.

Marshall, Y. and Alberti, B. (2014) 'A matter of Difference: Karen Barad, Ontology and Archaeological Bodies', Cambridge Archaeological Journal 24: 19-36.

McFadyen, L. (2007) 'Making Architecture', in D. Benson \& A. Whittle (eds) Building Memories: the Neolithic Cotswold Long Barrow at Ascott-under-Wychwood, Oxfordshire, pp. 348-54. Oxford: Oxbow.

Olsen, B. (2010) In Defense of Things: Archaeology and the Ontology of Objects. Plymouth: Altamira Press.

Olsen, B. (2012) 'After Interpretation: Remembering Archaeology', Current Swedish Archaeology 20: 11-34.

Olsen, B., Shanks, M., Webmoor, T. \& Witmore, C.L. (2012) Archaeology: the Discipline of Things. Berkeley, CA: University of California Press.

Piggott, S. (1958) 'The Excavation of the West Kennet Long Barrow: 1955-56, Antiquity 32: $235-42$.

Piggott, S. (1962) The West Kennet Long Barrow: Excavations 1955-56. London: Her Majesty's Stationary Office.

Pyyhtinen, O. and Tamminen, S. (2011) 'We Have Never Been Only Human: Foucault and Latour on the Question of the Anthropos', Anthropological Theory 11: 135-52. 
Shaviro, S. (2011) 'The Actual Volcano: Whitehead, Harman, and the Problem of Relations', in L.Bryant, N. Srnicek and G. Harman (eds) The Speculative Turn: Continental Materialism and Realism, pp. 279-90. Melbourne: Re.press.

Sørensen, M.L.S. (1997) 'Material Culture and Typology', Current Swedish Archaeology 5: 179-92.

Thomas, J. (2002) 'Archaeology's Humanism and the Materiality of the Body', in Y. Hamilakis, M. Pluciennik \& S. Tarlow (eds) Thinking Through the Body: Archaeologies of Corporeality, pp. 29-45. London: Klewer Academic/Plenum Publishers.

Thomas, J. \& Whittle, A. (1986) 'Anatomy of a Tomb: West Kennet Revisited', Oxford Journal of Archaeology 5: 129-56.

Tilley, C. (1994) A Phenomenology of Landscape: Places, Paths and Monuments. Oxford: Berg.

Watts, C. (ed.) (2013) Relational Archaeologies: Humans, Animals, Things. London: Routledge

Webmoor, T. \& Witmore, C.L. (2008) 'Things Are Us! A Commentary on Human/Things Relations Under the Banner of a 'Social Archaeology", Norwegian Archaeological Review 41: 1-18.

Whitehead, A.N. (1964) The Concept of Nature. Cambridge: Cambridge University Press.

Witmore, C.L. (2007) 'Symmetrical Archaeology: Excerpts of a Manifesto', World Archaeology 39: 546-62.

Witmore, C.L. (2012) 'The Realities of the Past: Archaeology, Object-orientations, Pragmatology', In B.R. Fortenberry \& L. McAtackney (eds), Modern Materials: Proceedings from the Contemporary and Historical Archaeology in Theory Conference 2009, pp. 25-36. Oxford: British Archaeological Reports. 